\title{
Low power interstitial Nd YAG laser photocoagulation in normal and neoplastic rat colon
}

\author{
K MATTHEWSON, T BARTON, M R LEWIN, J P O'SULlivaN, \\ T C NORTHFIELD, AND S G BOWN \\ From the National Medical Laser Centre and Surgical Unit, University College Hospital, London, and Norman \\ Tanner Gastroenterology Unit and Department of Pathology, St James Hospital, Balham, London
}

SUmmary The effects of low power (1-2 Watts), long exposure (30-400 seconds), interstitial Nd YAG laser therapy on dimethylhydrazine induced rat colonic neoplasms and normal rat colon have been studied. After a single exposure with appropriate laser parameters, dimethylhydrażine induced rat colonic neoplasms underwent coagulative necrosis, sloughed off over a four day period, and left an ulcer which healed within 28 days. Inadequate laser energy resulted in incomplete tumour necrosis whilst excessive laser power or energy increased the likelihood of perforation. Treatment of normal colon with 1 Watt for 30 seconds or longer resulted in coagulative damage which healed by granulation. Mean colonic bursting pressures were significantly decreased one hour after treatment with 1 Watt for 75 or 100 seconds compared with untreated colon $(\mathrm{p}<0 \cdot 05$ and $\mathrm{p}<0.001$ respectively) but not in colon treated with 1 Watt for 30 or 50 seconds. In animals treated with 1 Watt for 100 seconds mean bursting pressures were significantly lower than untreated animals when the animals were killed two, four, and seven days after lasering $(\mathrm{p}<0 \cdot 001$ in each case) but not in animals killed at 11,17 , or 21 days. The technique may be of value in the treatment of some inoperable colorectal cancers and sessile polyps in man.

Lasers are devices capable of producing a high intensity, monochromatic and collimated beam of light which can be focused onto the end of, and transmitted along narrow gauge optical fibres. These unique characteristics make them a highly convenient means of transmitting energy into living tissues. The $\mathrm{Nd}$ YAG laser produces relatively deeply penetrating, invisible, infrared light and is of proven value in the treatment of bleeding peptic ulcer ${ }^{1-3}$ and vascular anomalies of the gut..$^{+5}$ It has also been used to palliate a variety of foregut, ${ }^{67}$ hindgut, ${ }^{89}$ and bronchial" cancers and tumour destruction is usually achieved by positioning the laser fibre about $1 \mathrm{~cm}$ above the tissue to be treated and using high power settings $(60-80 \mathrm{~W})$ with short exposure durations $(0.5$ to $2 \mathrm{~s})$. Repeated exposures result in vapourisation of tumour with production of large quantities of smoke. Several treatments are usually required to remove large bulks of tumour.

Address for correspondence: Dr Ken Matthewson, Senior Registrar in Medicine. Southampton General Hospital, Tremona Road, Southampton SO9 4XY.

Received for publication 28 May 1987.
We have recently reported a different technique for producing tissue necrosis using the Nd YAG laser." This involves inserting the laser fibre into the substance of the tissue (interstitial placement) and using very low power settings of the order of 1 Watt and long exposure durations. There is a more gentle heating effect which in rat liver causes reproducible, well defined areas of necrosis which heal by granulation and fibrosis. The present study is an evaluation of this technique in the treatment of dimethylhydrazine induced rat colorectal cancer with access at colonoscopy. The effect of such treatment on normal rat colonic wall has also been studied.

\section{Methods}

Colonic tumours were induced in Wistar rats (180$250 \mathrm{~g}$ ) by weekly injections of dimethylhydrazine (DMH) as described by Filipe ${ }^{12}$ using a dosage of 40 $\mathrm{mg} / \mathrm{kg}$ for five weeks. This induces carcinogenesis in both fore and hind guts and the majority of animals had tumours in the descending colon within six 
months. A whole range of tumours from benign adenomas to invasive and metastasising carcinomas are produced. Some animals also develop ear canal tumours. Thirty tumour bearing animals were treated colonoscopically five to seven months after the course of DMH injections was started. Not all animals had external clinical signs of tumour formation such as rectal bleeding at the time of colonoscopy, although if these developed treatment was undertaken at the earliest opportunity.

Colonoscopy was done under intramuscular fentanyl and fluanisone (Hypnorm, JANSEN) sedation using a Fujinon FB SBF fibreoptic bronchoscope with a device connected for insufflating the colon through the biopsy channel. The descending colon could be cleared of stool by flushing water through the biopsy channel and good views to the splenic flexure were obtained. Attempts to pass the instrument beyond the splenic flexure invariably caused perforation. Before treatment, tumour size was extimated by opening biopsy forceps of known span within the lumen. A pulsed Nd YAG laser (system 2000, JK Lasers, Rugby, UK) was used to irradiate accessible tumours via a single $400 \mu \mathrm{m}$ diameter optical fibre which was passed down the biopsy channel and inserted interstitially into the tumour. In early experiments the black plastic coating over the surface of the laser fibre was stripped back for several centimetres from the fibre tip but it proved difficult to accurately position the tip of the fibre at the centre of the tumour and this resulted in an unacceptably high perforation rate. In subsequent experiments the plastic coating was only stripped back $2 \mathrm{~mm}$ from the fibre tip. The fibre was then pushed into the tumour until the black plastic coating abutted onto the tumour wall and it was then possible to be confident that the fibre tip was $2 \mathrm{~mm}$ below its surface. Laser light pulse duration was 100 us with a repetition rate of 40 pulses/s. Tumours were exposed to $1 \mathrm{~W}$ (average power) for $100-400 \mathrm{~s}$ with the exception of one tumour which received $2 \mathrm{~W}$ for $100 \mathrm{~s}$. Power at the tip of the laser fibre was measured before and after exposure using a Scientech 364 Power Energy Meter. Animals were killed one hour to 30 days later and the descending colon removed and fixed in formalin. Obvious tumours in other parts of the bowel were also removed and fixed in formalin to be used as histological controls. Histological sections were prepared using a haematoxylin and eosin stain and reported by an experienced histopathologist (JPOS) who was unaware whether that particular tumour had been lasered. Three animals were kept under regular colonoscopic and photographic review before death on the 30th day.

Eighty eight normal Wistar rats $(180-250 \mathrm{~g})$ were also colonoscoped using the above technique and the laser fibre pressed against the mucosa of the middescending colon with sufficient force just to cause
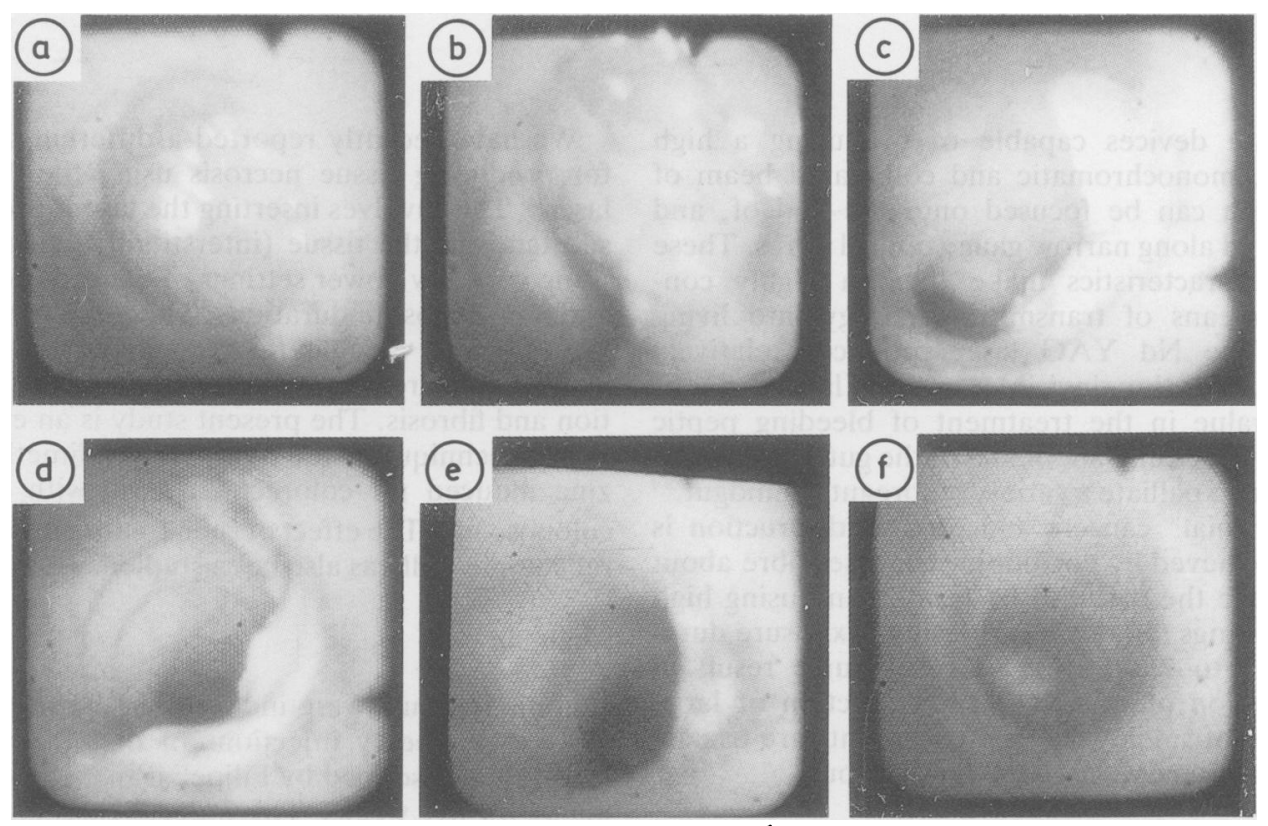

Fig. 1 Colonoscopic view of $8 \mathrm{~mm}$ diameter colonic tumour (a) before treatment, (b) immediately after interstitial exposure to Nd YA G laser light ( 1 Watt for 300 seconds), (c) at four days, (d) at seven days, (e) at 14 days, and (f) at 28 days. 
'tenting'. The fibre was held in this position until the colon had been exposed to laser light at $1 \mathrm{~W}$ for 30 to 100 seconds. Pulse duration and repetition rate were as for the tumour experiments. Animals were killed one hour to 24 days later and a $4 \mathrm{~cm}$ length of colon including the treated portion was removed. This was used either for immediate measurement of colonic bursting pressure $(n=68)$ or fixed in formalin for subsequent histological examination $(n=20)$. Bowel or mesentry which was adherent to the laser lesion was not stripped away as it was regarded as contributing to the tensile strength of the bowel wall. Ten additional animals which had not been lasered were used as controls for the colonic bursting pressure experiments.

Colonic bursting pressure was measured using a transducer (Model 23001, Amed Ltd, USA) and chart recorder (Oscillograph M10-120A, Micro Movements Ltd, UK) calibrated against a mercury column. One end of the colonic segment was tied off and the other connected to a closed circuit of tubing connecting the transducer, mercury column and a cylinder of air. The colonic segment was then held under water and the system filled with air at an initial rate of $1.3 \mathrm{mls} / \mathrm{s}$. When air bubbles suddenly escaped through the colonic wall a mark was made on the chart recorder to indicate bursting pressure.

Comparisons of means were done using Student's $t$ test. Values shown are means and the standard error of the mean.

\section{Results}

Tumours treated in the DMH prepared rats were polypoid and between 4 and $20 \mathrm{~mm}$ in diameter. The tumour shown in Figure 1a which was $8 \mathrm{~mm}$ in diameter was treated with $1 \mathrm{~W}$ for $300 \mathrm{~s}$. Immediately after treatment there was little visual effect apart from some dessication and shrinkage (Fig. 1b). At four days the tumour had necrosed and sloughed off leaving an ulcer creater (Fig. 1c). This increased in size until day 7 (Fig. 1d) but by 14 days this had almost healed (Fig. 1e) and by 28 days the site of treatment could not be found, either colonoscopically (Fig. 1f), or by dissecting the colon when it was subsequently removed. Histologically, the technique caused coagulative necrosis of tumours. This was either incomplete with a well defined boundary zone

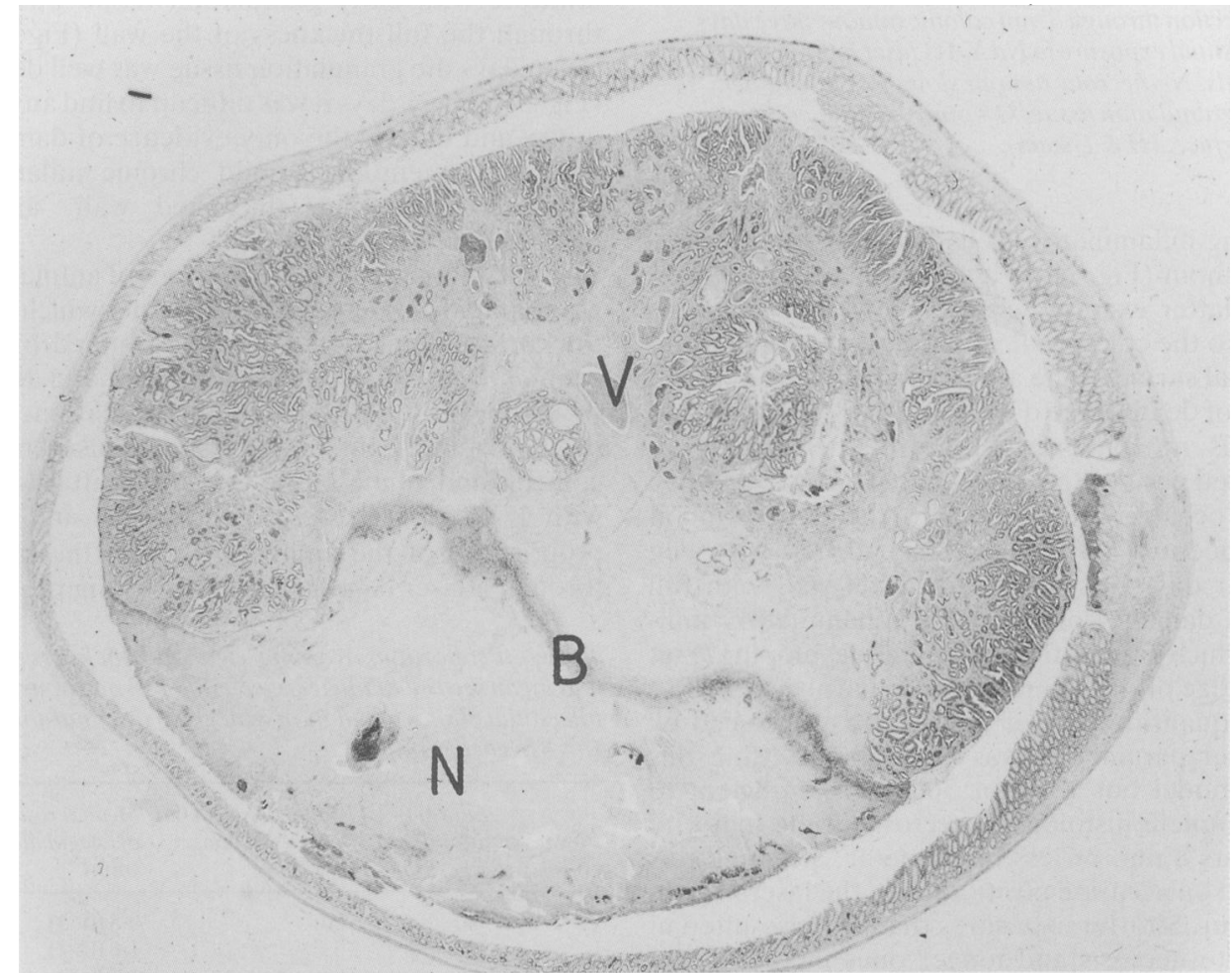

Fig. 2 Section through $15 \mathrm{~mm}$ diameter colonic tumour two days after interstitial exposure to Nd YAG laser light, I Watt for 200 seconds. $N=$ necrotic tumour, $V=$ viable tumour, $B=$ boundary zone containing inflammatory infiltrate. ( $H \& E$ stain) 


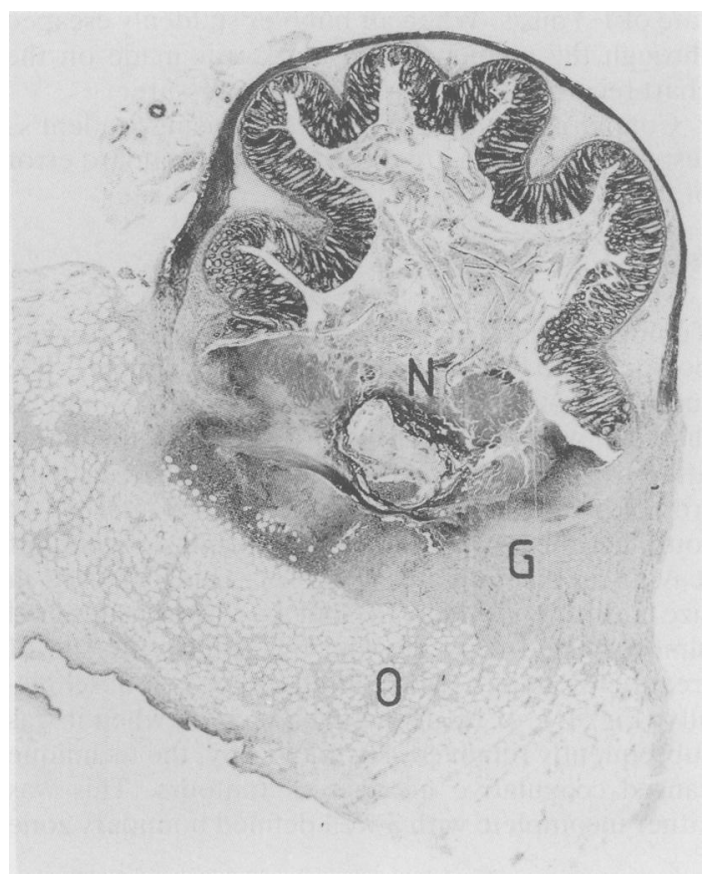

Fig. 3 Section through 8 mm colonic tumour three days after interstitial exposure to Nd YAG laser light, 1 Watt for 300 seconds. $N=$ necrotic tumour sloughing into lumen, $G=$ early granulation tissue, $O=$ omentum adherent to serosal surface. ( $H \&$ E stain).

containing inflammatory cells between necrotic and viable tumour (Fig. 2), or it appeared complete (Fig. 3 ). The latter example clearly shows full thickness damage to the colon wall with omentum adherent to the serosal surface. The animal had appeared well at the time of death three days after laser exposure, and there was no evidence of a free perforation or generalised peritonitis. Tumour in which coagulative necrosis occurred sloughed into the lumen and if there was entire tumour necrosis all that was seen after four days was ulcerated bowel wall with full thickness damage containing an inflammatory infiltrate in which granulation tissue was developing (Fig. 4). The edge of the ulceration was sharply defined.

Exact quantification of the necrosis produced by given laser parameters was not possible using this tumour model but $1 \mathrm{~W}$ for $300 \mathrm{~s}$ was sufficient to cause complete histological necrosis in the majority of tumours $8 \mathrm{~mm}$ or less in diameter, although this depended on accurate positioning of the laser fibre in the tumour. Shorter exposures than $300 \mathrm{~s}$ resulted in incomplete necrosis and longer ones increased the risk of complications, notably one case of enterocolic fistula formation which had received $1 \mathrm{~W}$ for $400 \mathrm{~s}$, and four perforations. Of the perforations one had been treated with $1 \mathrm{~W}$ for $400 \mathrm{~s}$, one with $2 \mathrm{~W}$ for $100 \mathrm{~s}$ and in two the laser fibre had passed through the tumour and treated normal bowel beyond it. These latter two were animals treated at the beginning of the project before the fibre tip had been modified. A third animal in which this happened and which received $1 \mathrm{~W}$ for $200 \mathrm{~s}$ did not perforate.

The immediate visual effect of exposing normal colonic mucosa was a central black spot where the fibre had been in contact with the mucosa and blanching of the surrounding area. The blanching was also apparent on the serosal surface of the colon in animals which developed full thickness damage. In animals killed two days post treatment omentum was loosely adherent over the treated area and by four to seven days it had become firmly adherent. Histologically, in those animals killed one hour after treatment, full thickness damage was seen even in some animals treated for only $30 \mathrm{~s}$. This was associated with complete loss of the mucosa and submucosa, and debris from these layers sloughed into the colonic lumen. The muscularis propria appeared attenuated and pale (Fig. 5a). At four days the treated area was still ulcerated and an inflammatory infiltrate with early granulation tissue was evident through the full thickness of the wall (Fig. 5b). At seven days the granulation tissue was well developed (Fig. 5c). By 21 days it was difficult to find any trace of injury and usually the only evidence of damage was adherent omentum, a mild chronic inflammatory infiltrate within the thickened wall, and little evidence of fibrosis (Fig. 1d).

The Table shows the proportions of animals undergoing bursting pressure experiments which had full thickness colonic damage as determined by careful examination of the serosal surface, and the mean diameter of the serosal area of coagulation. Figure 6 shows results of bursting pressure measurements for controls and animals killed one hour after treatment with $1 \mathrm{~W}$ for $30,50,75$, and $100 \mathrm{~s}$, and also the proportions of the animals in which the burst was through a laser damaged area. Bursting pressures in

Table Proportions of animals with full thickness damage and mean serosal diameter of coagulation one hour after interstitial photocoagulation with given laser parameters ( $n=8$ in each group)

\begin{tabular}{llll}
\hline $\begin{array}{l}\text { Power } \\
\text { W) }\end{array}$ & $\begin{array}{l}\text { Exposure } \\
\text { duration } \\
(s)\end{array}$ & $\begin{array}{l}\text { Proportion with full } \\
\text { thickness damage } \\
(\%)\end{array}$ & $\begin{array}{l}\text { Meanserosal diameter } \\
\text { of coagulation (range) } \\
(m m)\end{array}$ \\
\hline 1 & 30 & 50 & $0.8(0-3)$ \\
1 & 50 & 63 & $1.6(0-4)$ \\
1 & 75 & 88 & $1.9(0-4)$ \\
1 & 100 & 100 & $3.9(2-6)$ \\
\hline
\end{tabular}




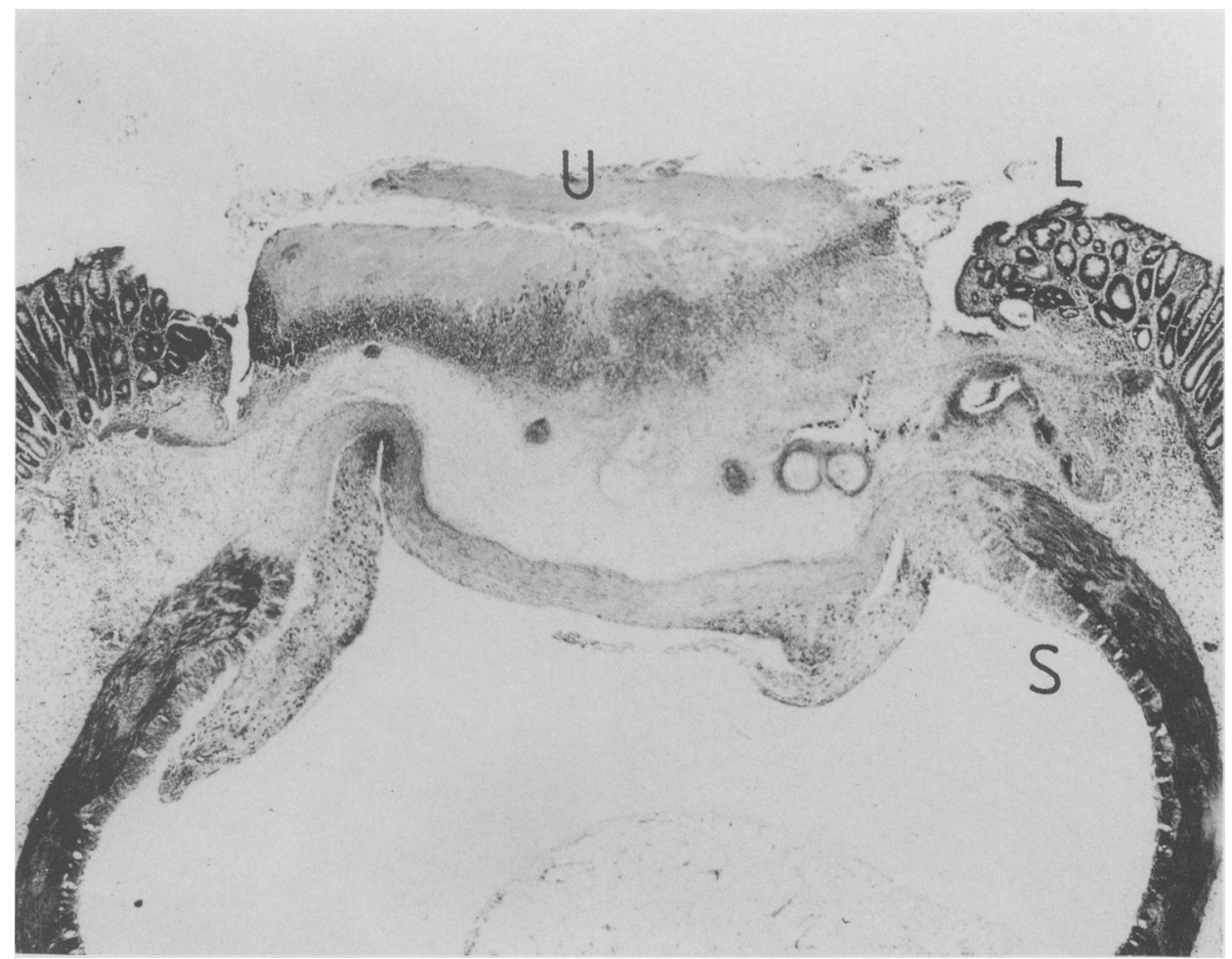

Fig. 4 Section through rat colon four days after interstitial exposure of an 8 mm diameter tumour to Nd YAG laser light, $I$ Watt for 300 seconds. $L=$ luminal surface, $S=$ serosal surface, $U=$ ulcer base containing residual necrotic tumour. ( $H \& E$ stain)

animals treated for 30 or $50 \mathrm{~s}$ were not significantly lower than controls and the burst usually occurred through a part of the bowel wall remote to the laser lesion. In those animals treated for 75 or $100 \mathrm{~s}$ the burst was usually through the laser lesion and there were significant decreases in bursting pressure compared with controls. Bursts in control animals were through a sudden longitudinal split whereas when they occurred through laser lesions it was usually in the form of small bubbles leaking through a pin-hole in the centre of the coagulated area. Figure 7 shows bursting pressures in controls and animals treated with $1 \mathrm{~W}$ for $100 \mathrm{~s}$ and killed at one hour, and two, four, seven, 11, 17, and 24 days, and the proportions of animals in which the burst was through the laser damaged area. Lowest bursting pressures were at two days but after this they progressively rose and had normalised by 11 days.

\section{Discussion}

This study has shown that it is possible to cause complete histological necrosis of dimethylhydrazine induced rat colorectal cancer with single interstitial placement of an optical fibre and a single prolonged exposure to low power Nd YAG laser light. Complications which occurred were the result of either using an inappropriately high power setting, too much energy, or of innaccurate positioning of the laser fibre tip. This particular tumour model was chosen because it was a convenient way of producing a large number of animals bearing tumours which have a considerable number of similarities to colorectal cancers in man and cause similar rectal bleeding, anaemia, mucous diarrhoea and obstruction. One disadvantage of the model was that nearly all animals developed tumours in parts of the gut not accessible to colonoscopic treatment. It was therefore not possible to carry out survival studies because even if the descending colon was cleared of tumour, animals would have died from tumours in other parts of the gut.

Bursting pressure has been widely used as a means of assessing the mechanical strength of intact colon, particularly after experimental surgical anastamoses, ${ }^{1314}$ and it has proved a satisfactory method of measuring the mechanical strength of lasered colon in this study. It was of interest in the 


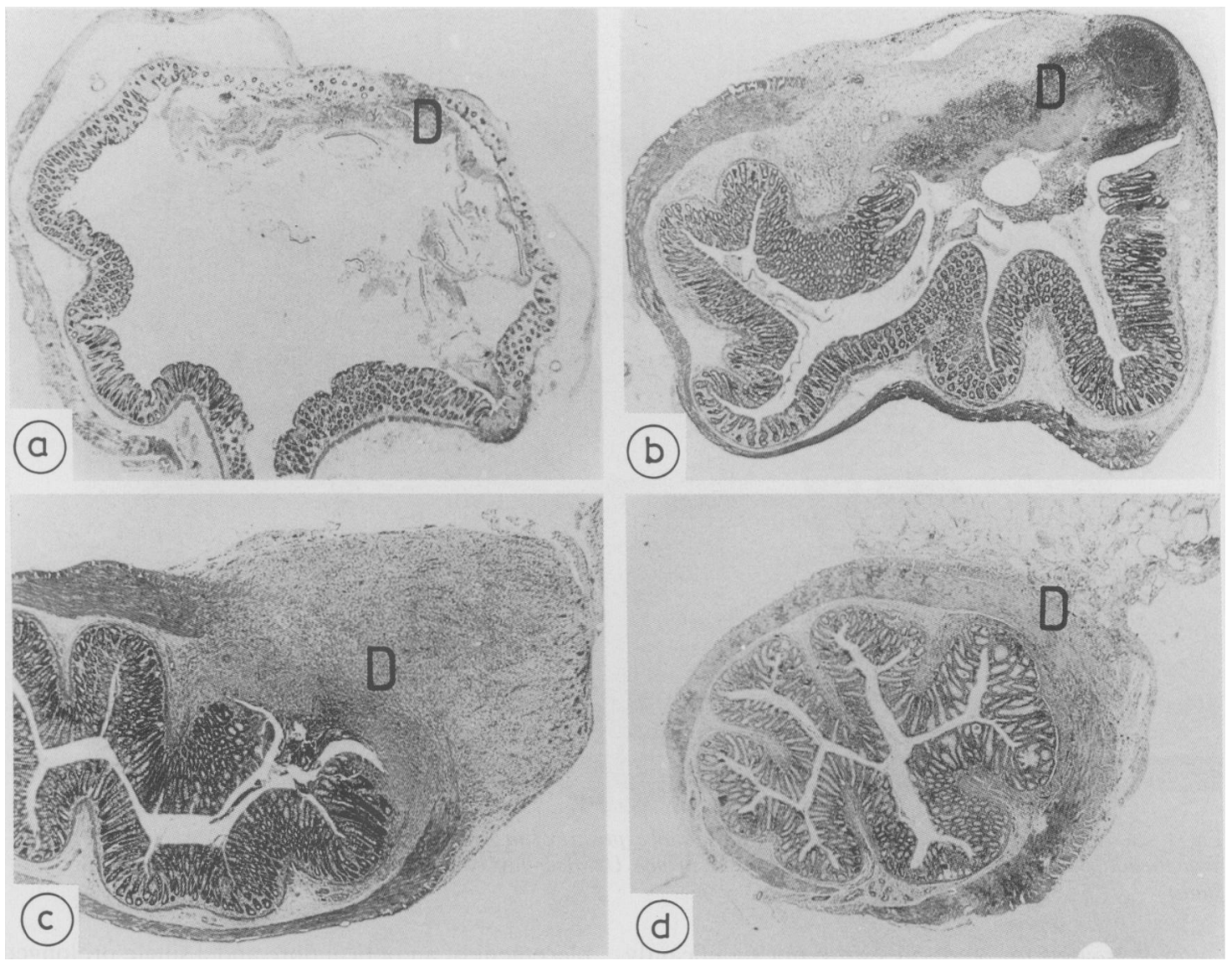

Fig. 5 Sections through normal rat colon after exposure to Nd YAG laser light, I Watt for 100 seconds. (a) one hour after exposure, (b) four days after exposure, (c) seven days after exposure, and (d) 21 days after exposure. $D=$ laser damaged area. ( $H \&$ Estain)

normal colon experiments that although full thickness histological damage was seen in some animals killed one hour after treatment for 30 or $50 \mathrm{~s}$, there was no significant decrease in bursting pressure compared with controls. It is possible that if these animals had been studied two days after lasering then significant decreases might have been found, because in the group treated for $100 \mathrm{~s}$ bursting pressures troughed at this time. Histological healing of these lesions was by granulation and this was reflected by a progressive rise in bursting pressures which returned to normal by 11 days. Rat colonic wall is little more than a thin membrane and it might be anticipated that larger quantities of laser energy could be put into the human colonic wall without undue loss of mechanical strength. It seems likely that the energy required to induce complete necrosis of large tumours will exceed the amount which could be safely used on normal bowel wall and selectivity of tumour damage will have to be achieved through accurate positioning of the fibre tip in the tumour.

Colorectal cancer is a common condition and significant numbers are inoperable because of metastatic disease or because the patient's medical condition precludes a general anaesthetic. In addition some patients will have recurrent disease after surgery. Such patients may have distressing symptoms including bleeding, rectal discharge and those of intestinal obstruction. Current high power noncontact Nd YAG laser technique are already proving of value in the palliation of these patients although several treatment sessions are required to remove large bulks of tumour. ${ }^{x y}$ In addition, the production of large quantities of smoke is unpleasant both for patient and clinician; rapid flow rates of coaxial carbon dioxide are required to cool the fibre tip and blow away the smoke causing colonic distension; and the treatment of tumour infiltrating the full thickness 


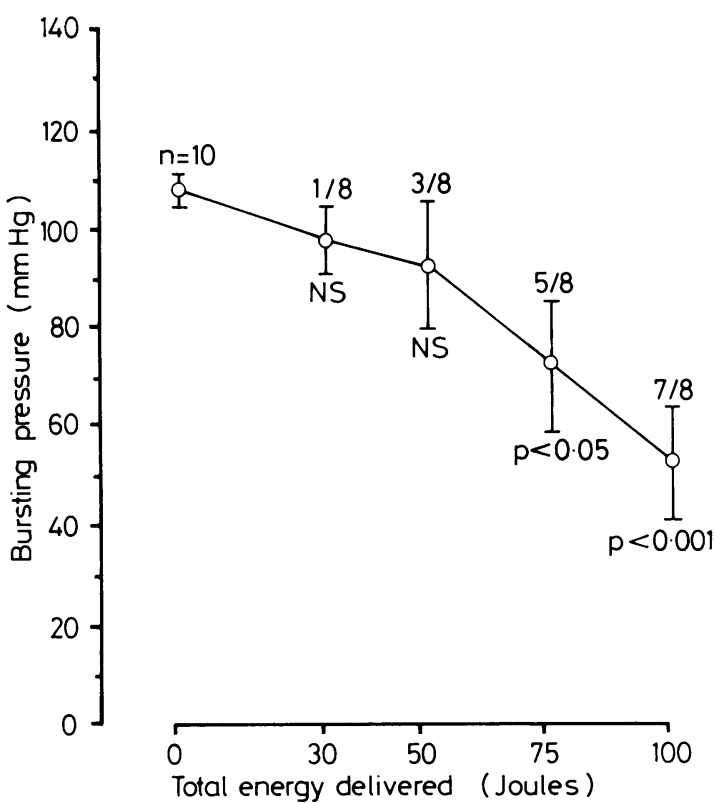

Fig. 6 Mean bursting pressure (+SEM) of normal rat colon one hour after exposure to given amounts of $N d Y A G$ laser light delivered at a power of 1 Watt. Proportions of colons in which the burst was through a visibly laser damaged area are shown above the mean bursting pressures. Significance values refer to comparisons with the control colons.

of the colonic wall is likely to carry a high risk of perforation. Using our technique large amounts of tumour might be rendered necrotic in a more precise way by multiple insertions of the laser fibre during one treatment session, virtually no smoke is produced, no coaxial carbon dioxide is required and it may be possible to treat tumour which is infiltrating the full thickness of the colonic wall by gentle heating with a low risk of perforation. In addition it should be possible to manufacture low power Nd YAG lasers for a fraction of the cost of the high power devices.

A more contentious area than the treatment of inoperable tumours is the primary treatment of colorectal cancers which could otherwise have been treated surgically. It is possible to eradicate villous adenomas of the rectum using laser techniques, ${ }^{15}$ and there are some advocates of other non-surgical techniques as the primary treatment of rectal cancers. ${ }^{16}$ It seems likely, however, that in those patients in whom surgery is possible, this will provide the most reliable means of achieving a cure.

In conclusion it has been shown that using an interstitial, low powered Nd YAG laser technique it is possible to remove all histological trace of accessible dimethylhydrazine induced rat colonic carcinomas. The technique can cause full thickness

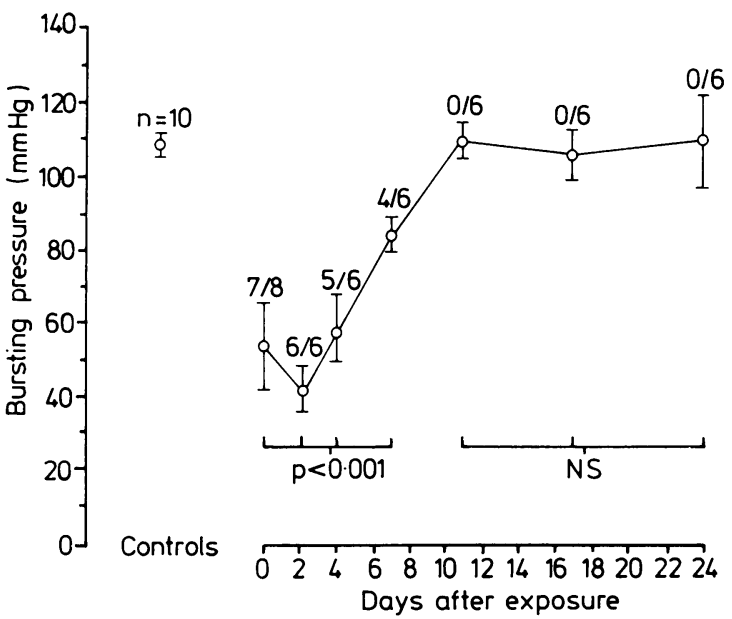

Fig. 7 Mean bursting pressure (+SEM) of normal colon after exposure to $\mathrm{Nd} Y A$ G laser light, 1 Watt for 100 seconds, against the number of days after exposure on which the animal was killed. Proportions of colons in which the burst was through a visibly laser damaged area are shown above the mean bursting pressures. Significance values refer to comparisons with control colons.

damage in normal rat colon after only $30 \mathrm{~s}$ at $1 \mathrm{~W}$, and $100 \mathrm{~s}$ at $1 \mathrm{~W}$ results in a decrease in bursting pressure to about half the normal value. Damage heals by granulation, however, and this is associated with normalisation of bursting pressures within 11 days. The technique may prove of value in the treatment of some inoperable colorectal carcinomas and sessile colonic polyps in man.

KM was supported by a grant from the Office of the Chief Scientist of the Department of Health and Social Security and SGB by a grant from the Imperial Cancer Research Fund.

\section{References}

1 Rutgeerts P, Vantrappen P, Broeckert L, et al. Controlled trial of YAG laser treatment of upper digestive haemorrhage. Gastroenterology 1982; 83: 410-6.

2 MacLeod IA, Mills PR, MacKenzie JF, Joffe SN, Russell RI, Carter DC. Neodymium yttrium aluminium garnet laser photocoagulation for major haemorrhage from peptic ulcers and single vessels: a single blind controlled trial. Br Med J 1983; 286: 345-8.

3 Swain CP, Kirkham JS, Salmon PR, Bown SG, Northfield TC. Controlled trial of Nd YAG laser photocoagulation in bleeding peptic ulcers. Lancet 1986; i: 1113-6.

4 Rutgeerts P, Van Gompel F, Geboes K, Vantrappen G, Broeckaert L, Coremans G. Long term results of treatment of vascular malformations of the gastrointestinal tract by neodymium YAG laser photocoagulation. Gut 1985; 26: 586-93. 
5 Bown SG, Swain CP, Storey DW, et al. Endoscopic laser treatment of vascular anomalies of the upper gastrointestinal tract. Gut 1985; 26: 1338-48.

6 Swain CP, Bown SG, Edwards DAW, Kirkham JS, Salmon PR, Clark CG. Laser recanalization of obstructing foregut cancer. BrJ Surg 1984; 71: 112-5.

7 Fleischer D, Sivak MV. Endoscopic Nd YAG laser therapy as palliative treatment for advanced adenocarcinoma of the gastric cardia. Gastroenterology 1984; 87: 815-20.

8 Mathus-Vleigen EMH, Tytgat GNJ. Nd YAG laser photocoagulation in gastroenterology: its role in palliation of colorectal cancer. Lasers Med Sci 1986; 1: 75-80.

9 Bown SG, Barr H, Matthewson K, et al. Endoscopic treatment of inoperable colorectal cancers with the $\mathrm{Nd}$ YAG laser. BrJ Surg 1986; 73: 949-52.

10 Hetzel MR, Nixon C, Edmonstone WM, et al. Laser therapy in 100 tracheobronchial tumours. Thorax 1985; 40: $341-5$.

11 Matthewson K, Coleridge-Smith P, O'Sullivan JP,
Northfield TC, Bown SG. Biological effects of intrahepatic Nd YAG laser photocoagulation in rats. Gastroenterology 1987; 93: 550-7.

12 Filipe MI. Mucus secretion in rat colonic mucosa during carcinogenesis induced by dimethylhydrazine. A morphological and histochemical study. BrJ Surg 1982; 69: $308-10$.

13 Hermann JB, Woodward SC, Pulaski EJ. Healing of colonic anastamoses in the rat. Surg Gynecol Obstet 1964; 119: 269-75.

14 Ward MWN, Danzi M, Lewin MR, Rennie MJ, Clark CG. The effects of subclinical malnutrition and refeeding on the healing of experimental colonic anastamoses. Gastroenterology 1985; 89: 832-7.

15 Brunetaud JM, Mosquet L, Houcke M, et al. Villous adenomas of the rectum. Results of endoscopic treatment with argon and Nd YAG lasers. Gastroenterology 1985; 89: 832-7.

16 Madden JL, Kandalaft SI. Electrocoagulation as a primary curative method in the treatment of carcinoma of the rectum. Surg Gynecol Obstet 1983; 157: 164-79. 